\title{
Objectively Measured Physical Activity and Sedentary Time of Suburban Toddlers aged 12-36 Months.
}

\author{
Louise Kelly ( $\sim$ lakelly@callutheran.edu ) \\ California Lutheran University \\ Allan Knox \\ California Lutheran University \\ Carlos Gonzalez \\ California Lutheran University \\ Patrick Lennartz \\ California Lutheran University \\ Jordan Hildebrand \\ California Lutheran University \\ Blake Carney \\ California Lutheran University \\ Spencer Wendt \\ California Lutheran University \\ Rebecca Haas \\ California Lutheran University \\ Mason Hill \\ California Lutheran University
}

\section{Research Article}

Keywords: pediatric, physical activity, sedentary behavior, ethnicity, tracking, Hispanic, African American

Posted Date: February 28th, 2022

DOI: https://doi.org/10.21203/rs.3.rs-1289646/v1

License: (c) (i) This work is licensed under a Creative Commons Attribution 4.0 International License. Read Full License 


\section{Abstract}

AIMS: assess differences in sedentary behavior and physical activity by gender; examine the interaction of ethnicity, gender, and overweight status on physical activity and sedentary behavior, and finally track physical activity in a subset of children aged 12-36 months over 1 year.

METHODS: During year one, 142 participants wore the GT3X Actigraph for 3 days. At 1-year follow-up a subset of 25 participants wore the Actigraph for 7 consecutive days. GLM, t-tests as appropriate were carried out to assess the influence of gender on physical activity level. Spearman rank correlations, percentage agreement and kappa statistics assessed tracking of physical activity.

RESULTS: There were no significant gender differences in any anthropometric measurements, sedentary behavior or MVPA ( $p>0.05$ ). There were also no significant gender, ethnicity, and overweight interaction for sedentary behavior, time sent in light PA and time spent at MVPA (p.0.05). For tracking, there was a moderate strength of agreement for MVPA.

CONCLUSION: A greater understanding of physical activity and sedentary behavior in toddlers is necessary.

\section{Introduction}

Pediatric obesity is a very serious problem in the United States, because of the adverse consequences in both the short and long term to their health. ${ }^{1,2}$ Obese children are at high risk for diseases such as Type 2 Diabetes ${ }^{3}$, cardiovascular disease ${ }^{4}$ and obesity related cancers ${ }^{5}$. It is currently estimated that 13.7 million children aged 2-19 years and $13.9 \%$ of children aged 2-to-5 are affected with obesity. ${ }^{6}$ The prevalence of obesity is considerably higher among minority populations, in 2017 the Centre for Disease Control ${ }^{7}$ publication reported Hispanics and nonHispanic blacks had a higher obesity prevalence compared with non-Hispanic Whites and Non-Hispanic Asians (25.8\%, 22.0\%, 14.1\% and 11\% respectively). Furthermore, while the participation in physical activity is low in the pediatric population, they are particularly low for Black and Hispanic. ${ }^{8}$ However, potential differences in physical activity and sedentary behavior levels of toddlers from different ethnic groups has yet to be established.

The dearth of research regarding the physical activity and time spent at sedentary behaviors in toddlers represents a crucial gap in the literature. The toddler years are of particular importance, as it has been established that the first 5 years of life are critical periods for the development of obesogenic behaviors $^{9-12}$. Furthermore, a large proportion of children have been shown to engage in high levels of screen time before the age of 3 years, thus significantly increasing time spent sedentary. Unfortunately, these physical activity and sedentary behaviors have been shown to track from childhood to adulthood ${ }^{13}$. Data has shown a decline in energy intake ${ }^{14,15}$ and habitual physical activity, and moderate to vigorous physical activity (MVPA), while sedentary behaviors, have dramatically increased. ${ }^{16,17}$ While the health consequences of physical activity have been well established for preschool aged children ${ }^{18}$, assessing physical activity in toddlers has not been a priority. This may be due to the belief that young children are typically engage in short and sporadic bursts of activity and the reactivity due to children's inherently curious nature and are therefore healthy. However, evidence has proven a relationship between adult-onset diseases originating in early childhood, placing an urgency in assessment of physical activity of toddlers.

While a plethora of data on physical activity and sedentary behavior of preschool and older children exists in the literature, there is a paucity of data on toddlers. This may be due to theoretical challenges measuring physical activity and sedentary behavior in toddlers. ${ }^{19}$ Current recommendations suggest 180 minutes of physical activity per day are needed for health in children aged 1-4. ${ }^{20}$ However, Reilly et al., suggests most young children are not meeting these recommendations as the majority of their time is spent in sedentary behavior. ${ }^{1}$ With the levels of sedentary behavior maybe more pronounced in minority communities but this is difficult to assess, as to our knowledge there have been no data published on ethnic differences in sedentary behavior and different intensities of physical activity

Tracking can be defined as the stability of a certain variable over time. ${ }^{21,22}$ Tracking is traditionally assessed by test-test correlations demonstrating normative stability. Normal stability of a behavior is high when individuals remain at the same relative position within the sample distribution. Knowing one's of relative position and maintenance of that position within one's cohort, is a helpful tool in quantifying whether a child will maintain his/her relative rank for physical activity and sedentary behavior within a group of children over time. ${ }^{23}$ Physical activity and sedentary behavior tracking studies not only quantify whether a child will maintain his or her relate rank for physical activity and sedentary within a cohort of children over time but also are useful predictors of a child's later physical activity and sedentary behavior, based on their initial behavior. ${ }^{13,24}$ Previous studies, reported low levels of tracking of total physical activity, MVPA and sedentary behavior in children aged $3+{ }^{22,25,26}$ no tracking data exists on children aged 12-36 months. Therefore, the aims of this study are as follows: 1) quantitatively describe levels of habitual physical activity in a contemporary sample of suburban children aged 12- to 36-months, 2) assess for gender differences in physical activity and sedentary behavior; 3 ) examine the specific effects of ethnicity, gender, and overweight status on objectively measured physical activity, and 4) quantify tracking of physical activity in a sub-set of children over 1 year.

\section{Research Methods And Procedures}




\section{Study Participants:}

A total of 142 children between the ages 12-36 months and their parents were recruited to participate in this study. Participants and their families were recruited from local private, community day care facilities, along with recruitment through word of mouth. For the present study the children were required to provide a minimum of 3 complete days of physical activity. Therefore, a sample of 100 children (53 boys, 47 girls) were included in the final analyses. A subsample of 25 children provided 7 days' physical activity at a 12-month follow-up. Parents were asked to report their child's gender and ethnicity. For a child to be included in a particular ethnicity parents and grandparents' descent had to be from the same ethnic group. The California Lutheran Universities Institutional Review Board approved the study, and informed written consent was obtained from the parent or guardian of each child. All methods were preformed in accordance with the relevant guidelines and regulations.

\section{Anthropometric Measures}

Using a SECCA stadiometer and a Tanita medical scale, and without shoes or socks height was measured to the closest $0.1 \mathrm{~cm}$ and body weight to closest $0.05 \mathrm{~kg}$. Gender specific weight and/or BMI percentiles for each child (where age appropriate) were determined using Epilnfo, Version 7 for $\operatorname{Mac}(\mathrm{CDC}$, Atlanta, GA).

\section{Physical Activity and Sedentary Behavior}

Habitual physical activity and sedentary behavior was assessed using the Actigraph GT3X accelerometer (Pensacola, Florida). The GT3X was securely attached to an elastic belt on the child's right hip as previously reported. ${ }^{27,28}$ Children continuously wore the GT3X under clothing for a minimum of three consecutive days. A minimum of 6 hours per day (i.e., 18 hours over 3 days) of activity monitoring between the hours of 6:00am and 10:00pm were required for inclusion in our final analysis. Parents were instructed to fasten accelerometers on when the child wakes up in the morning and remove it only for sleeping and bathing. Parents were also asked to log when the accelerometer was put on and removed. Data were collected in 15-second epochs. Non-wear time was defined as consecutive zero counts for $\geq 20$ mins, and there therefore excluded from analyses as previously suggested by Vanderloo and Tucker. ${ }^{29}$ To quantify the time spent in varying intensities of physical activity and in sedentary behavior, cut-points from a previously published, peer-reviewed study were applied. ${ }^{30}$ Sedentary activity (SED) was considered $\leq 181$ counts/15 sec epoch. Light physical activity (LPA) had a range of 182-434 counts/ 15 sec epoch. Moderate to vigorous physical activity (MVPA) was $\geq 435$ counts/15 sec epoch. Children whose data did not meet the minimum time requirement of three days with six hours per day were not included in the final analysis.

\section{Statistical Analysis}

All data were checked for normality before statistical analysis, using descriptive statistics, histograms with normal distribution curves, and Anderson-Darling (AD) normality tests. Student's t-tests were carried out to assess the influence of gender on physical activity level. General linear models (GLM) were used to examine the relationship between the independent variables (i.e., ethnicity, gender, and overweight status) and the dependent variables (i.e., total physical activity (cpm), sedentary behaviors, light physical activity, and MVPA). Analysis of variance (ANOVA) was used to examine the main and interaction effects of ethnicity, gender, and overweight status. To assess Tracking Spearman rank correlations were calculated to examine tracking of physical activity and sedentary behavior between baseline and 12-month follow-up. Percentage agreement and kappa statistics were calculated between baseline and 12-month follow-up to determine the likelihood that a particular child would be classified in

the same group from year to year. ${ }^{31} \mathrm{~A}$ kappa value of $<.20$ represented a poor strength of agreement, .21 to .40 a fair strength of agreement, .41 to .60 a moderate strength of agreement, .61 to .80 a good strength of agreement, and .81 to 1.00 a very good strength of agreement. ${ }^{31}$ All analysis was conducted using SPSS (Mac version 24) and an alpha of 0.05 for all statistics.

\section{Results}

A total of 142 children aged 12-36 months were recruited to the study. Final analysis was conducted on 100 children, 42 children were not included for the following reasons; 30 failed to provide the minimum GT3X wear time, and 12 refused testing. At baseline participants included 47 girls and 53 boys. The mean age at baseline was $1.8 \pm 0.5$ months. At baseline t-tests showed no significant gender differences for age ( $p=0.057)$, height $(p=0.07)$, weight $(p=0.34)$, BMI percentile $(p=0.51)$, or weight percentile $(p=0.32)$. The mean accelerometer measurement period was 8.03 waking hours per day (range 6.3-9.9 hours) at baseline. The baseline characteristics are shown in Table 1.

A sub sample of children ( $n=25 ; 10$ girls and 15 boys) had their physical activity assessed 1 year later. The mean age at 1-year follow-up was $2.74 \pm 0.5$ months. T-Tests showed no significant gender differences for age $(p=0.039)$, height $(p=0.63)$, weight $(p=0.61)$, BMI percentile $(p=$ 0.42 ), or weight percentile $(p=0.51)$. The mean accelerometer measurement period was 9.12 waking hours per day (range $6.8-10.2$ hours). The 1year follow-up characteristics are shown in Table 1. 
At baseline, participants spent $56.24 \pm 6.64 \%$ of time at SB, $1.8 \pm 2.6 \%$ at LPA and $41.7 \pm 7.0 \%$ in MVPA. T-Tests showed no significant gender difference for SB (girls $=57.27 \pm 6.18$ vs. boys $=55.4 \pm 6.9 ; p=0.807$ ), or MVPA (girls $=40.77 \pm 7.17$ vs. boys $42.44 \pm 6.95 ; p=0.714$ ). However, there was a significant gender difference for LPA with boys spending more time at this PA intensity than girls $($ boys $=2.12 \pm 3.1 \mathrm{vs}$. girls $=1.40 \pm 1.86 ; p=$ 0.031). When we examined the effects of ethnicity gender and overweight status on physical activity, results from the GLM showed no significant gender, ethnicity, and overweight interaction for sedentary behavior $(p=0.682)$, time sent in light PA $(p=0.15)$ and time spent at MVPA (both $p=$ 0.64) (see Table 2).

Spearman rank correlation and kappa statistics are presented in Table 3. Spearman rank correlation for SB was $r=0.63(p<0.02)$ and kappa was $0.28(p=0.89)$ which has a fair strength of agreement ${ }^{31}$. Spearman rank correlation for LPA was very low $r=-0.003(p<=0.99)$ and kappa was $0.018(p=0.56)$ which has a poor strength of agreement. Whereas, Spearman rank correlation for MVPA was $r=0.66(p=0.02)$ and kappa was $0.47(p=0.007)$ which has a moderate strength of agreement.

\section{Discussion}

It is well documented that early years of development are critical years for the development of an active lifestyle and healthy living behaviors. Unfortunately, it is this exact period that we know the least about the impact of physical activity and the consequences of sedentary behavior. In 2019, the World Health Organization estimated that 38 million children under the age of 5 were overweight or obese. Declines in physical activity and increases in sedentary behavior have significantly contributed to the epidemic of obesity in childhood ..$^{14,15}$ Therefore, the health implications of physical activity during the early years cannot be disregarded. Directly, targeting physical activity and sedentary behavior is undoubtedly the only evidence-based approach for obesity prevention. ${ }^{2}$

To our knowledge, we are the first, in the United States, and the largest study to objectively measure habitual physical activity, sedentary behavior and quantify tracking in a suburban representative sample of toddlers. Furthermore, we are the first study, to assess ethnic differences in habitual physical activity and sedentary behavior in such a young age group. The key findings from our study show toddlers, regardless of their gender or ethnic identity spend a considerable amount of their waking hours engaged in sedentary behaviors. This study suggests that gender differences in sedentary behavior and MVPA commonly seen in children from preschool age and onwards was not observed at this very young age. However, we did observe gender differences with boys spending more time in light PA compared with girls. Our findings that children are spending a large amount of their waking time in sedentary behavior are consistent with a growing body of evidence. ${ }^{1,32}$

However, a direct comparison of our data to other published data is rather difficult given the array of tools to assess physical activity and sedentary behavior in this in this age group. A study by Carson and Kuzik found somewhat similar results to our study. Their study comprised of Urban Canadian toddlers found that females, those from ethnic minority groups and toddlers from families of lower socio economic groups were significantly more sedentary by engaging in more video and computer use ${ }^{33}$. A review by Prioreschi and colleagues reported on the physical activity levels of children under 2 years, however, due the vast array of methods used to assess physical activity synthesis of the results impossible. While only 6 of the studies used accelerometers, none of the studies reported on sedentary behavior or tracking of these behaviors. ${ }^{34}$

A review and meta-analysis of 47 studies, showed children a spent similar amount of time in sedentary behavior to those in this current study. However, there were some limitations to this analysis of the Pereira review, namely accelerometer wear time criterion was not applied, therefore there is a possibility that sedentary behavior data used may not accurately assess daily habitual levels. ${ }^{35}$ Other studies have also reported similarly high levels of sedentary behavior to those found in the current study. However, we have reported higher levels of time spent in MVPA and less time in light physical activity. This may in part be due to our sample population being a suburban one and conducted in a warmer climate, as weather has been shown to affect participation in physical activity. ${ }^{36}$ This study also suggestion that gender differences in engagement in light physical activity is similar to those found in older children. But these differences should be viewed with caution. A mean difference of 0.72 between the sexes in accelerometer output should not interpreted as a $0.72 \%$ difference in light physical activity.

Of foremost concern are the ever-widening inequalities on obesity prevalence. Differences in physical activity (PA) may contribute to this risk but few data exist in childhood, and to our knowledge no studies exist in toddlers. There are blatant differences in childhood adiposity and metabolic disorders within certain ethnic minority groups. ${ }^{37,38}$ These differences may be associated with existing disparities such as socioeconomic and ethnic differences. Literature in adult and older children's population show ethnicity as a crucial predictor of obesity and metabolic health. Studies have found that in general nonwhite children are less physically active and more sedentary than their white peers. ${ }^{39}$ While the results of our study found no significant gender, ethnicity and obesity interaction, it should be noted that young Asian females spent the most time in SED, African American boys spent the most time in LPA, and Hispanic boys spent the most time in MVPA and the lowest time in SB. Our results would suggest that ethnic differences in physical activity and sedentary behaviors are established much earlier than anticipated, leading to the need to intervene at a much early than every originally thought.

To our knowledge we are the first study to report tracking of physical activity and sedentary behavior in toddlers. The results of our study showed tracking coefficients between baseline as 12-month follow-up showed moderate levels of tracking for sedentary behavior and MVPA and a 
negligible correlation for LPA. Kappa statistics ranged from - 0.02 to 0.47 , demonstrating maintenance of MVAP and sedentary behavior but not LPA in toddlers. These results again emphasize the need for successful interventions grounded in the comprehension of the very intricate of these behaviors in this age group. While there is a very small body of evidence of physical activity behaviors in toddlers, to our knowledge there are no currently published studies reporting on the objectively measured tracking sedentary behavior or tracking of these behaviors in this young age group. There are published data on tracking in preschool aged children, however, but only a few have used accelerometers and others have used a range of methods such as questionnaires in a variety cultures and age groups. ${ }^{25,40-42}$ Jackson and colleagues reported similar levels of tracking to ours in a sample of preschool aged children using an older model of the Actigraph ${ }^{40}$. In contrast, other studies have found lower levels found lower levels of tracking in children aged $3-5$ years by using Actigraph, heart rate and direct observations. ${ }^{25,43,44}$

It is important to note that the present study has several limitations. First, our relatively low number of participants in our tracking study. While tracking studies in older age groups had larger sample sizes, it was difficult for us to assess the sample size need for this study as no other tracking studies in this age group are currently published. However, given that our group was tracked over a 12-month period, using objective measurements, age-appropriate cut-offs and robust statistical techniques to assesses tracking, we are confident that our report of moderate levels of tracking in this age group is correct. Lastly, the low numbers of Asian males and African American girls recruited to the study. Several strengths should also be noted; our study is the first relatively large socioeconomically representative sample of very young suburban children. Secondly, the precision of our assessment of physical activity and sedentary in this young group; and the use of age-appropriate cut-points with 15 second epochs and we defined a non-wear time as 20 minutes of consecutive zero's, thus capturing a more accurate picture of this age groups patterns and finally, the multiple indices to capture tracking. In addition to the traditional use of correlations, we calculated KAPPA statistics, by calculating these we were able to reaffirm the extent to which a participant remained in their respective physical activity and sedentary behavior categories over the 12 months' period.

\section{Conclusion}

In summary, this is the first study to objectively measure habitual physical activity, sedentary behavior, quantify tracking and to assess ethnic differences in habitual physical activity and sedentary behavior in a suburban representative sample of toddlers. The results of this study raises the possibility, that interventions targeting toddlers, especially minority children should focus on understanding the factors that contribute to ethnicity disparities in physical activity, understand the factors that contribute to their patterns of activity and sedentary behavior, and then focus on promoting culturally appropriate interventions to increase physical activity, decrease sedentary behavior and in turn, change the trajectory of these negative patterns becoming lifelong behaviors.

\section{Declarations Conflict of Interest}

The authors declare no conflict of interest.

\section{Funding}

No funding to declare.

\section{Acknowledgements}

We express our sincerest gratitude to the participants and their families for making this study possible.

\section{Patient Consent:}

IRB approved consent and assent was acquired for all participants.

\section{Data Availability:}

The dataset used and/or analysed during this study are available from the corresponding author on reasonable request.

\section{Contributors:}


Study conception and design of the study was conducted by $\mathrm{LK}, \mathrm{MH}, \& \mathrm{BC}$. LK and AK advised on all statistical aspects and interpreted the data. LK performed the statistical analysis. All authors drafted the manuscript. All authors reviewed the manuscript and approved the final version to be published. LK, MH \& RH had full access to all the data in the study and take responsibility for the integrity of the data and the accuracy of the data analysis.

\section{References}

1. Reilly JJ, Jackson DM, Montgomery C, Kelly LA, Slater C, Grant S, Paton JY. Total energy expenditure and physical activity in young Scottish children: mixed longitudinal study. Lancet. 2004; 17:363(9404):211-2.

2. Reilly JJ, Wilson M, Summerbell CD, Wilson DC. Obesity diagnosis, prevention and treatment: evidence based answers to common questions. Arch Dis Child. 2002; 86:392-5.

3. Goran MI, Ball GD, Cruz ML. Obesity and risk of type 2 diabetes and cardiovascular disease in children and adolescents. The Journal of Clinical Endocrinology \& Metabolism. 2003; 88(4):1417-27.

4. Lahey R, Khan SS. Trends in obesity and risk of cardiovascular disease. Current epidemiology reports. 2018; 5(3):243-51.

5. Must A, Strauss RS. Risks and consequences of childhood and adolescent obesity. International journal of obesity. 1999;23(2):S2-11.

6. Hales CM, Carroll MD, Fryar CD, Ogden CL. Prevalence of obesity among adults and youth: United States, 2015-2016. 2017.

7. Johnson NB, Hayes LD, Brown K, Hoo EC, Ethier KA. CDC National Health Report: leading causes of morbidity and mortality and associated behavioral risk and protective factors-United States, 2005-2013.

8. Ceaser TG, Fitzhugh EC, Thompson DL, Bassett Jr DR. Association of physical activity, fitness, and race: NHANES 1999-2004. Medicine and science in sports and exercise. 2013;45(2):286-93.

9. Reilly JJ, Armstrong J, Dorosty AR, Emmett PM, Ness A, Rogers I, Steer C, Sherriff A. Early life risk factors for obesity in childhood: cohort study. Bmj. 2005;330(7504):1357.

10. Timmons BW, LeBlanc AG, Carson V, Connor Gorber S, Dillman C, Janssen I, Kho ME, Spence JC, Stearns JA, Tremblay MS. Systematic review of physical activity and health in the early years (aged 0-4 years). Applied Physiology, Nutrition, and Metabolism. 2012;37(4):773-92.

11. Reilly JJ, Penpraze V, Hislop J, Davies G, Grant S, Paton JY. Objective measurement of physical activity and sedentary behavior: review with new data. Archives of disease in childhood. 2008;93(7):614-9.

12. Downing KL, Hnatiuk J, Hesketh KD. Prevalence of sedentary behavior in children under 2 years: a systematic review. Preventive medicine. 2015;78:105-14.

13. Kelly LA, Reilly JJ, Jackson DM, Montgomery C, Grant S, Paton JY. Tracking physical activity and sedentary behavior in young children. Pediatric exercise science. 2007;19(1):51-60.

14. Troiano RP, Flegal KM. Overweight children and adolescents: description, epidemiology and demographics. Pediatrics. 1998; 101:497-505.

15. Reilly JJ, Dorosty AR. Epidemic of obesity in UK children. Lancet. 1999; 354:1874-5.

16. Dietz WH. The role of lifestyle in health: the epidemiology and consequences of inactivity. Proc Nutr Soc. 1996; 55:829- 40.

17. Robinson TN. Reducing children's television viewing to prevent obesity: a randomised controlled trial. JAMA. 1999; 282: $1961-7$.

18. Taylor RW, Murdoch L, Carter P, Gerrard DF, Williams SM, Taylor BJ. Longitudinal study of physical activity and inactivity in preschoolers: the FLAME study. Medicine and science in sports and exercise. 2009;41(1):96-102.

19. Cliff DP, Reilly JJ, Okely AD. Methodological considerations in using accelerometers to assess habitual physical activity in children aged $0-5$ years. Journal of science and medicine in sport. 2009;12(5):557-67.

20. Candian Society of Exercise Physiology. Canadian physical activity guidelines for the early years (0-4 years).

2012. http://www.csep.ca/CMFiles/Guidelines/CSEP_PAGuidelines_early-years_en.pdf. Accessed Jan 152015.

21. Twisk JW, Kemper HC, van Mechelen W. Tracking of physical activity from childhood to adulthood: a review. Obes. Facts. $2009 ; 2$ (3) 187-195.

22. Rauner A, Jekauc D, Mess F, Schmidt S, Woll A. Tracking physical activity in different settings from late childhood to early adulthood in Germany: the MoMo longitudinal study. BMC Public Health. 2015;15:391.

23. Fuentes RM, Notkola IL, Shemeikka S, Tuomilehto J, Nissinen A. Tracking of body mass index during childhood: a 15-year prospective population-based family study in eastern Finland. Int J Obes Relat Metab Disord. 2003;27(6):716-21

24. Pate RR, Baranowski TO, Dowda M, Trost SG. Tracking of physical activity in young children. Medicine \& Science in Sports \& Exercise. 1996; 28; 92-96.

25. Kelly LA, Reilly JJ, Jackson DM, Montgomery C, Grant S, Paton JY. Tracking physical activity and sedentary behavior in young children. Pediatr Exerc Sci. 2007;19(1):51-60. 
26. Swaminathan S, Selvam S, Thomas T, Kurpad AV, Vaz M. Longitudinal trends in physical activity patterns in selected urban south Indian school children. The Indian journal of medical research. 2011;134(2):174.

27. Kelly, L.A., J.J. Reilly, S.C. Fairweather, S. Barrie, S. Grant, and J.Y. Paton. Comparison of two accelerometers for assessment of physical activity in pre-school children. Pediatr. Exerc. Sci. 16:324-333, 2004.

28. Kelly LA, Reilly JJ, Grant S, Paton JY. Low physical activity levels and high levels of sedentary behavior are characteristic of rural Irish primary school children. Irish medical journal. 2005; 98(5):138-41.

29. Vanderloo LM, Tucker P. An objective assessment of toddlers' physical activity and sedentary levels: a cross-sectional study. BMC Public Health. 2015;15(1):1-0.

30. Kelly LA, Villalpando J, Carney B, Wendt S, Haas R. Development of Actigraph GT1M Accelerometer Cut-Points for Young Children Aged 12-36 Months. J Athl Enhanc 5: 4. of. 2016; 4:2.

31. Muñoz, S.R., and S.I. Bangdiwala. Interpretation of Kappa and B statistics measures of agreement. J. Appl. Stat. 1997; 24:105-111.

32. LeBlanc AG, Spence JC, Carson V, Connor Gorber S, Dillman C, Janssen I, Kho ME, Stearns JA, Timmons BW, Tremblay MS. Systematic review of sedentary behavior and health indicators in the early years (aged 0-4 years). Applied Physiology, Nutrition, and Metabolism. 2012;37(4):753-72.

33. Carson, V., \& Kuzik, N. (2017). Demographic correlates of screen time and objectively measured sedentary time and physical activity among toddlers: a cross-sectional study. BMC Public Health, 17(1), 1-11.

34. Prioreschi A, Micklesfield LK. A scoping review examining physical activity measurement and levels in the first 2 years of life. Child Care Health Dev. 2016;42(6):775-783

35. Pereira JR, Cliff DP, Sousa-Sá E, Zhang Z, Santos R. Prevalence of objectively measured sedentary behavior in early years: Systematic review and meta-analysis. Scand J Med Sci Sports. 2019;29(3):308-328.

36. Fisher, A., J.J. Reilly, C. Montgomery, L.A. Kelly, A. Williamson, D.M. Jackson, J.Y. Paton, and S. Grant. Seasonality in physical activity and sedentary behavior in young children. Pediatr. Exer. Sci.2005; 37: 684-688.

37. Razak F, Anand S, Vuksan V, Davis B, Jacobs R, Teo KK, Yusuf S. Ethnic differences in the relationships between obesity and glucosemetabolic abnormalities: a cross-sectional population-based study. International journal of obesity. 2005;29(6):656-67.

38. Freedman DS, Khan LK, Serdula MK, Ogden CL, Dietz WH. Racial and ethnic differences in secular trends for childhood BMI, weight, and height. Obesity. 2006;14(2):301-8.

39. Gordon-Larsen P, Adair LS, Popkin BM. Ethnic differences in physical activity and inactivity patterns and overweight status. Obesity research. 2002;10(3):141-9.

40. Jackson DM, Reilly JJ, Kelly LA, Montgomery C, Grant S, Paton JY. Objectively measured physical activity in a representative sample of 3-to 4year-old children. Obesity research. 2003;11(3):420-5.

41. Nyberg G, Ekelund C, Marcus C: Physical activity in children measured by accelerometry: stability over time. Scand J Med Sci Sports 2009;19:30-35.

42. Kristensen PL, Møller NC, Korsholm L, Wed- derkopp N, Andersen LB, Froberg K: Tracking of objectively measured physical activity from childhood to adolescence: the European youth heart study. Scand J Med Sci Sports 2008;18:171-178.

43. Benham-Deal, T. The stability and tracking of physical activity in young children. Med. Sci. Sports Exerc. 31:S315, 1999.

44. Pate, R.P., S.G. Trost, M. Dowda, et al. Tracking of physical activity, physical inactivity, and health-related physical fitness in rural youth. Pediatr. Exerc. Sci. 11:364-376, 1999.

\section{Tables}

\section{Table 1}

\section{Participants Characteristics}




\begin{tabular}{|c|c|c|c|c|}
\hline & \multicolumn{2}{|c|}{ Cross-Sectional Study_( $\mathrm{n=100})$. } & \multicolumn{2}{|c|}{1 Year Follow-up Study_(n-25). } \\
\hline & Girls $(n=47)$ & Boys $(n=53)$ & Girls $(n=10)$ & Boys $(n=15)$ \\
\hline Age (years) & $1.81 \pm .0 .49$ & $1.89 \pm .0 .59$ & $3.0 \pm .0 .47$ & $2.54 \pm .0 .52$ \\
\hline Height (m) & $0.84 \pm .0 .16$ & $0.89 \pm .0 .07$ & $1.00 \pm .0 .44$ & $0.94 \pm .0 .53$ \\
\hline Weight (kg) & $13.06 \pm .1 .93$ & $13.45 \pm .1 .67$ & $16.14 \pm .2 .91$ & $15.49 \pm .1 .57$ \\
\hline BMI $\left(\mathrm{kg} / \mathrm{m}^{2}\right)$ & $17.45 \pm .2 .83$ & $16.56 \pm .1 .00$ & $16.03 \pm .1 .98$ & $17.24 \pm .1 .87$ \\
\hline Weight Percentile (\%) & $57.53 \pm .30 .21$ & $64.35 \pm .20 .87$ & $64.22 \pm .25 .83$ & $73.00 \pm .23 .76$ \\
\hline BMI Percentile (\%) & $61.73 \pm .33 .48$ & $56.23 \pm .25 .42$ & $55.12 \pm .36 .83$ & $70.17 \pm .32 .22$ \\
\hline
\end{tabular}

Note: all date are means and St Dev; ${ }^{*}$ denotes significance; ${ }^{0}$ denotes a trend for significance

Table 2

Participants Characteristics by Ethnicity

\begin{tabular}{|c|c|c|c|c|c|c|c|c|}
\hline & $\begin{array}{l}\text { White } \\
\text { Girls }(n=19)\end{array}$ & $\begin{array}{l}\text { White } \\
\text { Boys }(n=19)\end{array}$ & Hispanic Girls $(n=15)$ & $\begin{array}{l}\text { Hispanic } \\
\text { Boys }(n=18)\end{array}$ & $\begin{array}{l}\frac{\text { Asian }}{\text { Girls }} \\
(n=7)\end{array}$ & $\begin{array}{l}\frac{\text { Asian }}{\text { Boys }} \\
\left.\frac{(n=2)}{n}\right)\end{array}$ & $\begin{array}{l}\frac{\text { African }}{\text { American Girls }} \\
\frac{(n=3)}{}\end{array}$ & $\frac{\frac{\text { African }}{\text { American Boys }}}{(n=17)}$ \\
\hline Age (yrs) & $1.7 \pm 0.5$ & $1.8 \pm .5$ & $1.85 \pm .41$ & $2.1 \pm 0.7$ & $1.9 \pm 0.6$ & $1.0 \pm \pm^{0}$ & $1.5 \pm 0.7$ & $2.0 \pm .5$ \\
\hline $\begin{array}{l}\text { Height } \\
\text { (m) }\end{array}$ & $0.88 \pm .08$ & $0.89 \pm 0.6$ & $0.83 \pm 0.2$ & $0.91 \pm .01$ & $0.85 \pm 0.1$ & $0.81 \pm .1$ & $0.68 \pm .4$ & $0.88 \pm .1$ \\
\hline $\begin{array}{l}\text { Weight } \\
\text { (kg) }\end{array}$ & $12.9 \pm 2.2$ & $13.3 \pm 1.6$ & $13.3 \pm 2.2$ & $14.1 \pm 2.1$ & $12.2 \pm .8$ & $12.5 \pm .3$ & $14.1 \pm 0.5$ & $13.2 \pm 1.4^{*}$ \\
\hline $\begin{array}{l}\text { BMl tile } \\
\text { (\%) }\end{array}$ & $45.4 \pm 36.4$ & $51.6 \pm 23.3$ & $73.1 \pm 34.3$ & $59.7 \pm 31.8$ & $49.0 \pm 15.7$ & & $84.4 \pm 17.4$ & $64.5 \pm 20.6$ \\
\hline $\begin{array}{l}\text { Weight } \\
\text { tile (\%) }\end{array}$ & $49.1 \pm 31.0$ & $60.8 \pm 18.4$ & $59.8 \pm 4.4$ & $67.7 \pm 29.4$ & $51.9 \pm 23.9$ & $74.4 \pm 2.1$ & $94.9 \pm 1.7$ & $65.0 \pm 6.1$ \\
\hline SB (\%) & $54.2 \pm 6.5$ & $56.9 \pm 7.6$ & $59.7 \pm 4.4$ & $53.8 \pm 7.5^{\star}$ & $60.3 \pm 5.7$ & $55.8 \pm 5.7$ & $56.6 \pm 7.0$ & $54.9 \pm 6.2$ \\
\hline LPA (\%) & $1.9 \pm 2.8$ & $1.1 \pm 0.2$ & $1.0 \pm 0.4$ & $2.2 \pm 3.3$ & $1.0 \pm 0.1$ & $1.2 \pm .2$ & $1.2 \pm .1$ & $3.2 \pm 4.2$ \\
\hline MVPA(\%) & $43.9 \pm 7.3$ & $41.9 \pm 7.6$ & $37.6 \pm 6.2$ & $44.0 \pm 7.9 *$ & $38.5 \pm 5.6$ & $43.0 \pm 6.0$ & $42.2 \pm 7.1$ & $41.8 \pm 6.1$ \\
\hline
\end{tabular}

Note: all date are means and St Dev; * denotes significance; ${ }^{\square}$ denotes a trend for significance; SED (\%) denotes percentage of time spent in sedentary behavior, LPA (\%) denotes percentage of time spent in light physical activity, and MVPA denotes percentage of time spent in moderate to vigorous physical activity

Table 3

Spearman Rank Order Correlations, and Kappa statistics to assess Tracking over 1 year

\begin{tabular}{|c|c|c|c|c|c|}
\hline & \multicolumn{2}{|c|}{ Spearman Rank Correlation } & \multirow[t]{2}{*}{ Percentage Agreement (\%) } & \multirow[t]{2}{*}{ KAPPA } & \multirow[t]{2}{*}{ Strength } \\
\hline & $R$ value & $P$ value & & & \\
\hline $\mathrm{SB}(\%)$ & 0.626 & $0.02 *$ & 28.6 & 0.89 & Fair Strength \\
\hline LPA (\%) & -0.003 & 0.99 & 1.8 & 0.56 & Poor Agreement \\
\hline MVPA(\%) & 0.662 & $0.02 *$ & 46.9 & $0.007 *$ & Moderate Strength \\
\hline
\end{tabular}

Note: * denotes significance 